\title{
Photoinduced stepwise bending behavior of photochromic diarylethene crystals
}

\author{
KITAGAWA, D., TANAKA, R., \& KOBATAKE, S.
}

\begin{tabular}{|c|c|}
\hline Citation & CrystEngComm, 18(38): 7236-7240 \\
\hline Issue Date & $2016-10-14$ \\
\hline Type & Journal Article \\
\hline Textversion & author \\
\hline Right & $\begin{array}{l}\text { This is the peer reviewed version of the following article: KITAGAWA, D., TANAKA, } \\
\text { R., \& KOBATAKE, S. (2016). Photoinduced stepwise bending behavior of } \\
\text { photochromic diarylethene crystals. CrystEngComm. 18, 7236-7240., which has been } \\
\text { published in final form at https://doi.org/10.1039/C6CE00607H . } \\
\text { This is not the published version. Please cite only the published version. } \\
\text { この論文は出版社版でありません。引用の際には出版社版をご確認ご利用ください。 }\end{array}$ \\
\hline URI & $\begin{array}{l}\text { http://dlisv03.media.osaka-cu.ac.jp/il/meta_pub/G0000438repository_14668033-2016 } \\
\text {-18-7236 }\end{array}$ \\
\hline DOI & Info:doi/ 10.1039/C6CE00607H \\
\hline
\end{tabular}

SURE: Osaka City University Repository

http://dlisv03.media.osaka-cu.ac.jp/il/meta_pub/G0000438repository

KITAGAWA, D., TANAKA, R., \& KOBATAKE, S. (2016). Photoinduced stepwise bending behavior of photochromic diarylethene crystals. CrystEngComm. 18, 7236-7240. 


\section{CrystEngComm}

\section{ARTICLE}

\section{Photoinduced stepwise bending behavior of photochromic diarylethene crystals}

Received 00th January 20xx, Accepted 00th January 20xx

DOI: $10.1039 / x 0 x \times 00000 x$

www.rsc.org/

\author{
Daichi Kitagawa, Rika Tanaka, and Seiya Kobatake*
}

Diarylethene crystals were found to exhibit photoinduced stepwise bending behavior. The bending rate changed significantly during continuous irradiation with ultraviolet (UV) light. This is a new type of photomechanical motion reported previously for various photoresponsive molecular crystals. Furthermore, the delayed bending behavior was observed even after UV light was turned off. The mechanism for the stepwise bending is discussed.

\section{Introduction}

The direct conversion of light energy to mechanical energy in photomechanical materials is very interesting and challenging in both basic and applied research. Such photomechanical materials have been widely investigated by many researchers. Photomechanical materials usually consist of photoresponsive molecules with ordered alignment, and photomechanical motion is induced by strain generated by photoreaction of the molecules in the materials. As representative examples of photomechanical materials, liquid crystal polymers and organic molecular crystals have been developed. ${ }^{1}$ In particular, organic molecular crystals have attracted much attention because they can be used as photoactuators at the mesoscopic scale. ${ }^{2-8}$ There are at least four important challenges in the research on photomechanical crystals: (i) investigation of new compounds that exhibit photomechanical motion, (ii) basic research on the mechanical properties of materials, (iii) practical applications of photomechanical motion, and (iv) investigation of new types of photomechanical motion. In the case of (i), various compounds that exhibit a photomechanical effect have been reported to date, such as diarylethene, ${ }^{9-21}$ furyl fulgide, ${ }^{22}$ azobenzene, ${ }^{23-27}$ salicylidene aniline, ${ }^{28}$ anthracene derivatives, ${ }^{29-35}$ 4-chlorocinnamic acid, ${ }^{36}$ 1,2-bis(4-pyridyl)ethylene salt, ${ }^{37}$ and benzylidenedimethylimidazolinone. ${ }^{38}$ Recently, it has been reported that the gold(I) isocyanide complex also exhibits the photomechanical effect. ${ }^{39}$ In the case of (ii), the Young's modulus, maximum stress, and bending rate of crystals have been estimated in detail because they are essential for the design and evaluation of photomechanical motion. ${ }^{12,15,17-19}$ In the case of (iii), applications of bending behavior including gearwheel rotation, ${ }^{15}$ the lifting of heavy metal objects, ${ }^{12}$ and current switching ${ }^{19}$ have been reported so far. Such demonstrations suggest that photomechanical crystals can serve as photoactuators. In the case of (iv), there are various

Department of Applied Chemistry, Graduate School of Engineering, Osaka City University, 3-3-138 Sugimoto, Sumiyoshi-ku, Osaka 558-8585, Japan.

Fax: +8166605 2797; Tel: +8166605 2797;

E-mail: kobatake@a-chem.eng.osaka-cu.ac.jp

† Electronic supplementary information (ESI) available: Detailed experimental data (Fig. S1-S5), and movie of photoinduced stepwise bending and delayed bending (Video S1-S3).]. See DOI: 10.1039/c000000x/ types of photomechanical motion, such as contraction, ${ }^{10,13,18}$ expansion, ${ }^{17}$ bending, ${ }^{12,15,17-21}$ curling, ${ }^{11}$ twisting, ${ }^{16}$ and fragmentation ${ }^{14}$ in diarylethene crystals. Various types of motion are attractive for the production of new types of photomechanical actuators and to generate complex motion. Therefore, the investigation of new photomechanical motion is necessary for the development of photomechanical crystals.

Here, we report a new example of photomechanical motion of diarylethene crystals. A diarylethene, 1,2-bis(2-methyl-5-(4-( $p$ toluyloxymethyl)phenyl)-3-thienyl)perfluorocyclopentene (1a in Fig. 1) was synthesized and the photomechanical motion of the needlelike crystals was investigated. Crystals of 1a exhibited photoinduced stepwise bending behavior, which is a new type of photomechanical motion that differs from that reported previously. The mechanism of this unique bending behavior is discussed based onexperimental results, such as the repeatability of bending and the delayed bending behavior.

\section{Results and discussion}

Diarylethene 1a was synthesized according to a procedure described in the literature. ${ }^{40}$ Needle-like crystals of $\mathbf{1 a}$ can be obtained by recrystallization from $n$-hexane/ether solution. Single crystal X-ray crystallographic analysis indicated the crystal system and space group for 1 a were monoclinic and $P 2 / \mathrm{n}$, respectively, as summarized in Table S1. ${ }^{40} \mathrm{Fig}$. S1 shows the molecular packing of 1a. A diarylethene molecule and a half of an $n$-hexane molecule were included in the asymmetric unit. All diarylethene molecules in the crystal exist in the photoreactive anti-parallel conformation. The

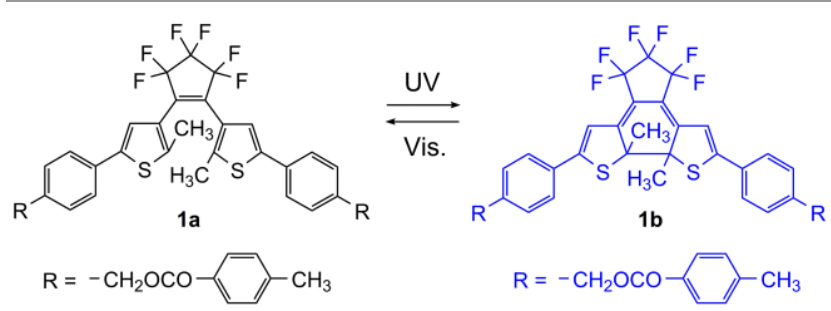

Fig. 1 Molecular structure of diarylethene 1a. 
(a)

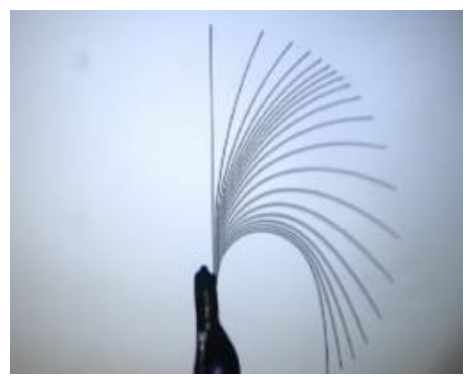

(b)

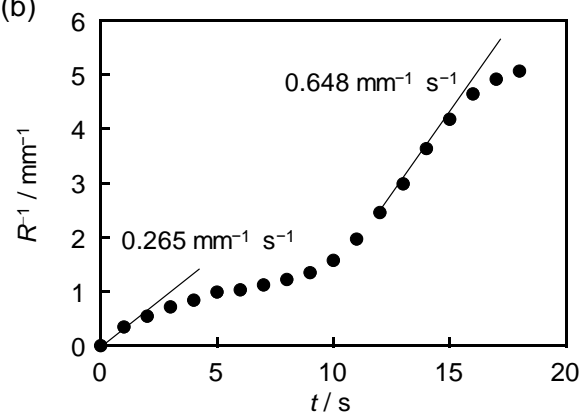

Fig. 2 (a) Stepwise photoinduced crystal bending upon irradiation with UV light. The photograph was superimposed for 20 frames of each $1 \mathrm{~s}$. (b) Change in curvature $\left(R^{-1}\right)$ relative to irradiation time $(t)$ with UV light.

distance between the reactive carbons was determined to be 3.556(3) $\AA$, which is sufficiently short to undergo photocyclization in the crystalline phase. ${ }^{41}$ When ultraviolet (UV) light was irradiated to the large-sized crystal, the color of the crystal changed from colorless to blue, in which the visible absorption maximum was observed at $590 \mathrm{~nm}$ (Fig. S2).

When UV light was irradiated to a small crystal of 1a, the crystal exhibited a bending behavior, as shown in Fig. 2 and Video S1. Fig. 2 shows a superimposition of photographs taken at intervals of $1 \mathrm{~s}$ to help visualize the temporal change of the bending behavior. When irradiated with UV light, the crystal first largely bent away from the light source and then the motion gradually became slow (from 0 to $6 \mathrm{~s}$, the first step). This is typical bending behavior observed for other diarylethene crystals. ${ }^{12,15,17-21}$ However, further irradiation of the crystal with UV light resulted in further significant bending (from 7 to $18 \mathrm{~s}$, the second step). The bending rate during the first and second steps is clearly different. This is the first example of photoinduced bending with a stepwise bending rate. The curvature of bending $\left(R^{-1}\right)$ in each frame was plotted against the UV irradiation time $(t)$ to evaluate the difference in the bending rate between the first and second steps. The bending rates during the first and second steps were thus determined to be 0.265 and 0.648 $\mathrm{mm}^{-1} \mathrm{~s}^{-1}$, respectively, which were calculated from the initial slope of the curve fitting in the first step and the maximum slope of the curvature change in the second step. This result indicates that the bending rate in the second step is approximately twice as fast as that in the first step.

To comprehend the mechanism of the stepwise bending behavior, the repeatability of bending was investigated. Fig. 3a shows the results of examining the repeatability for bending in the first step. When irradiated with UV light for $2 \mathrm{~s}$, the crystal bent (a)

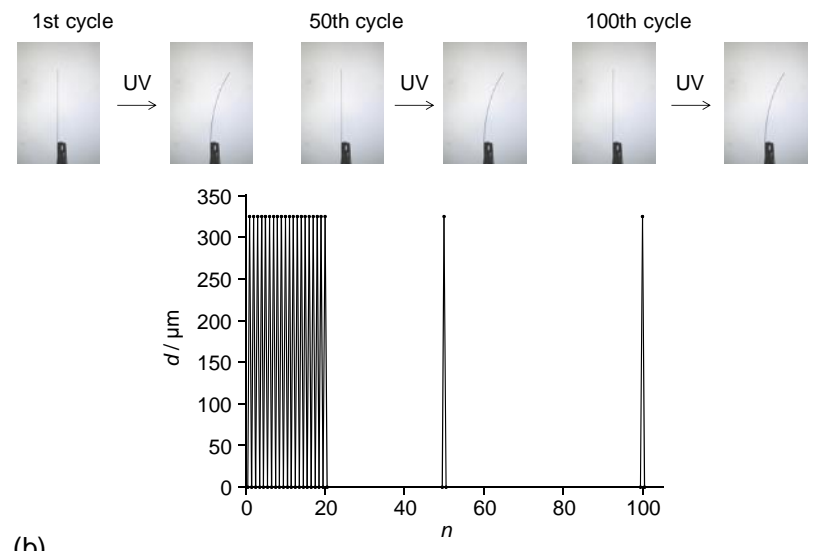

(b)
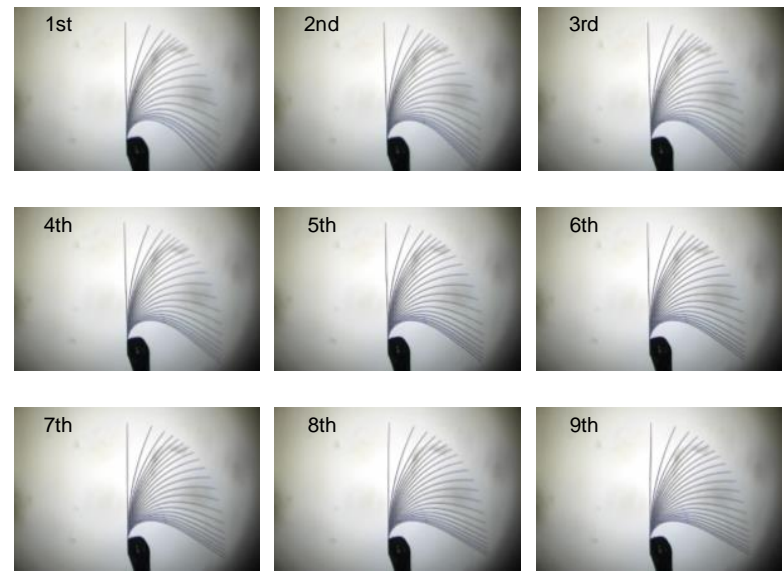

Fig. 3 (a) Reversible photoinduced bending of crystal 1a only in the first step upon alternating irradiation with ultraviolet $(365 \mathrm{~nm}$ ) light for $2 \mathrm{~s}$ and visible $(>500 \mathrm{~nm}$ ) light for $1 \mathrm{~min}$. $d$ and $n$ shows the tip displacement and cycle number, respectively. (b) Repeatability of the bending behavior of crystal 1a upon alternating irradiation with UV light for $20 \mathrm{~s}$ and visible (> $500 \mathrm{~nm}$ ) light for a long time.

away from the incident light source and the tip displacement $(d)$ was approximately $325 \mu \mathrm{m}$. Upon irradiation with visible light for 1 min, the bent crystal returned to its initial straight form. The reversible bending observed in the first step could be repeated for over 100 cycles. After 100 cycles of bending in the first step, the crystal exhibited the bending behavior similar to the stepwise bending upon irradiation with UV light for $20 \mathrm{~s}$ (Video S2). The crystal returned to the initial straight form by irradiation with visible light. These results indicate that there is no difference in the crystal motion during the first step, even after 100 repeated cycles. The repeatability of the bending for the second step upon UV irradiation was also investigated, and the results are shown in Fig. $3 \mathrm{~b}$. The change in curvature was also plotted and is shown in Fig. S3. Fig. 3b shows the superimposition of photographs taken at intervals of $1 \mathrm{~s}$. In the 1st cycle, the crystal clearly exhibited stepwise bending. However, as the number of cycles increased, the crystal tended not to exhibit the stepwise bending behavior. After the 9th cycle, the crystal exhibited bending without stepwise motion, which indicates that the bending rate of the crystal did not change during the bending motion. 

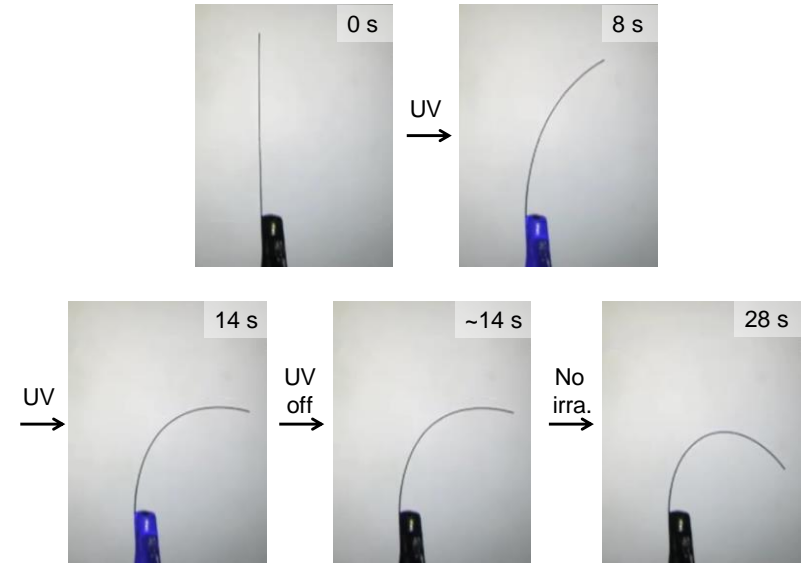

Fig. 4 Photoinduced crystal bending behavior of crystal 1a when the UV light irradiation was turned off during the second step.

Furthermore, in the course of study, delayed bending behavior was observed in the photoinduced bending of crystal 1a. Fig. 4 and Video S3 show the bending behavior of crystal 1a when the UV irradiation was turned off during the second step. When irradiated with UV light, the crystal bent away from the light source and gradually tended not to bend. Upon further irradiation with the UV light, the crystal began to bend significantly. This is the same as the stepwise bending shown in Fig. 3. After irradiation for $14 \mathrm{~s}$, the UV light was turned off. From previous reports on the bending of diarylethene crystals, bending stops when the UV light irradiation is turned off because the bending is induced by strain generated in the crystal from the photochromic reaction of diarylethene molecules from the open-ring isomer to the closed-ring isomer. ${ }^{10,12}$ However, in this case, the crystal continued to bend even after the UV light irradiation was turned off, which suggests that the significant bending in the second step cannot be only ascribed to the photochromic reaction of diarylethene molecules in the crystal.

To determine what changes the crystal packing, we first examined the effect of a mechanical stimulus on crystal 1a. After the crystal was manually bent many times as shown in Fig. S4, the photoinduced stepwise bending behavior was observed. This result indicates that the change in the crystal packing that induces the stepwise bending cannot be ascribed to the mechanical stimuli. Furthermore, changes in the physical properties of crystal 1a, such as the melting point were examined before and after cycles of alternating irradiation with UV and visible light. Figs. S5 and S6 show the melting behavior of crystal 1a before and after many cycles of alternating irradiation with UV and visible light. Before photoirradiation, the crystal began to melt at $90{ }^{\circ} \mathrm{C}$ and ended melting at $92{ }^{\circ} \mathrm{C}$, as shown in Fig. S5. On the other hand, after the irradiation cycles, the crystal started melting at $85^{\circ} \mathrm{C}$ and finished melting at $86^{\circ} \mathrm{C}$, as shown in Fig. S6. Fig. S7 also shows differential scanning calorimetry (DSC) traces for crystal 1a. Before photoirradiation, the crystal exhibited large endothermic behavior due to the crystal melting at $95{ }^{\circ} \mathrm{C}$. On the other hand, after the irradiation cycles, the crystal exhibited a broad and weak endothermic peak at around $90{ }^{\circ} \mathrm{C}$. These results clearly suggest that the crystal packing could be changed by the many cycles of alternating irradiation with UV and visible light. Although in situ Xray crystallographic analysis was attempted to confirm the change of the crystal packing, this could not be carried out because the crystals that exhibit the stepwise bending behavior are too small and thin to measure. Measurement of powder X-ray diffraction

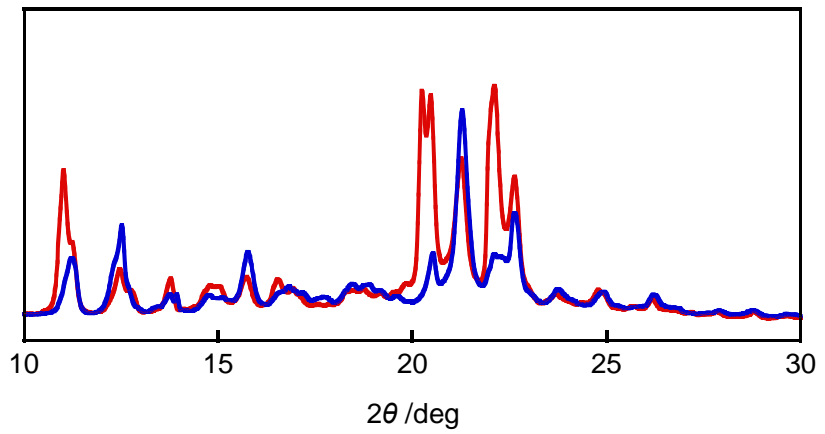

Fig. 5 Powder X-ray diffraction patterns before (red) and after (blue) many cycles of alternating irradiation with UV and visible light.

patterns was conducted. Fig. 5 shows X-ray diffraction profiles before and after the many cycles of alternating irradiation with UV and visible light. The diffraction profile after photoirradiation was not identical to that before photoirradiation. This result clearly indicates that the crystal packing could be changed by many cycles of alternating irradiation with UV and visible light and that the crystallinity was maintained.

Although the mechanism for the stepwise bending has yet to be clarified, based on the results presented here, we propose a mechanism. The bending in the first step is ascribed to the photochromic reaction of diarylethene molecules from the openring isomer to the closed-ring isomer. This is supported by the reversibility of the bending motion; bending in the first step could be repeated for over 100 cycles. On the other hand, the bending in the second step may be ascribed to a change of the crystal packing, such as a phase transition. The change in crystal packing begin with increased conversion from the open-ring isomer to the closed-ring isomer by the photochromic reaction.

\section{Conclusions}

The photomechanical motion of 1,2-bis(2-methyl-5-(4-( $p$ toluyloxymethyl)phenyl)-3-thienyl)perfluorocyclopentene crystals was investigated. Crystal 1a exhibited unique stepwise bending behavior, in which the bending rate changed significantly during continuous irradiation with UV light. This is a new type of photomechanical motion that has not been reported previously. Although the bending during the first step can be repeated for over 100 cycles upon alternating irradiation with UV and visible light, the bending in the second step exhibited different behavior after several cycles. Moreover, delayed bending behavior can be observed even after the UV light was turned off during the second step. From these results, a mechanism for the stepwise bending was proposed, in which the bending during the second step may be ascribed to a change of the crystal packing, such as a phase transition.

\section{Experimental}

General. The photoinduced bending behavior of diarylethene crystals was observed using a Keyence VHX-500 digital microscope. UV irradiation was carried out using a Keyence UV-LED UV-400 (365 $\mathrm{nm}$ ) light source. The light intensity on the crystal surface was 55 $\mathrm{mW} \mathrm{cm}^{-2}$. Visible light irradiation was carried out using a halogen 
lamp (100 W). Differential scanning calorimetry (DSC) was conducted using a Hitachi DSC-7000X calorimeter.

Determination of the bending rate. The edge of a rod-like crystal was fixed to a glass capillary and a fluorescent material was painted on the glass capillary. The fluorescence of the glass capillary provides the onset time of UV irradiation. The value of curvature was plotted against the UV irradiation time $(t)$. The bending rates during the first and second steps were calculated from the initial slope of the curve fitting in the first step and the maximum slope of curvature change in the second step.

Materials. Diarylethene 1a was synthesized according to a procedure described in the literature. ${ }^{40}$

\section{Acknowledgements}

This work was partly supported by a Grant-in-Aid for Scientific Research on Innovative Areas "Photosynergetics" (No. 26107013) from the Ministry of Education, Culture, Sports, Science and Technology (MEXT), Japan. D.K. appreciates Research Fellowships of the Japan Society for the Promotion of Science (JSPS) for Young Scientists. The authors also thank Nippon Zeon Co., Ltd. for providing octafluorocyclopentene.

\section{Notes and references}

1. Y. Yu, M. Nakano, and T. Ikeda, Nature, 2003, 425, 145-145.

2. T. Ikeda, J. Mamiya, and Y. Yu, Angew. Chem. Int. Ed., 2007, 46, 506-528.

3. Irie, T. Fukaminato, K. Matsuda, and S. Kobatake, Chem. Rev., 2014, 114, 12174-12277.

4. T. Kim, L. Zhu, R. O. Al-Kaysi, and C. J. Bardeen, ChemPhysChem, 2014, 15, 400-414.

5. M. Irie, Bull. Chem. Soc. Jpn., 2008, 81, 917-926.

6. S. Kobatake, and D. Kitagawa, In Advances in Organic Crystal Chemistry, Comprehensive Reviews 2015, ed. R. Tamura, and M. Miyata, Springer, 2015, pp. 533-547

7. N. K. Nath, M. K. Panda, S. C. Sahoo, and P. Naumov, CrystEngComm, 2014, 16, 1850-1858.

8. P. Naumov, S. Chizhik, M. K. Panda, N. K. Nath, and E. Boldyreva, Chem. Rev., 2015, 115, 12440-12490.

9. M. Irie, S. Kobatake, and M. Horichi, Science, 2001, 291, 17691772.

10. S. Kobatake, S. Takami, H. Muto, T. Ishikawa, and M. Irie, Nature, 2007, 446, 778-781.

11. K. Uchida, S. I. Sukata, Y. Matsuzawa, M. Akazawa, J. J. D. de Jong, N. Katsonis, Y. Kojima, S. Nakamura, J. Areephong, A Meetsma, and B. L. Feringa, Chem. Commun., 2008, 326-328.

12. M. Morimoto, and M. Irie, J. Am. Chem. Soc., 2010, 132 14172-14178.

13. L. Kuroki, S. Takami, K. Yoza, M. Morimoto, and M. Irie, Photochem. Photobiol. Sci., 2010, 9, 221-225.

14. S. Kobatake, H. Hasegawa, and K. Miyamura, Cryst. Growth Des., 2011, 11, 1223-1229.

15. F. Terao, M. Morimoto, and M. Irie, Angew. Chem. Int. Ed. 2012, 51, 901-904.

16. D. Kitagawa, H. Nishi, and S. Kobatake, Angew. Chem. Int. Ed., 2013, 52, 9320-9322.

17. D. Kitagawa, and S. Kobatake, J. Phys. Chem. C, 2013, 117 20887-20892.

18. D. Kitagawa, and S. Kobatake, Photochem. Photobiol. Sci. 2014, 13, 764-769.
19. D. Kitagawa, and S. Kobatake, Chem. Commun., 2015, 51 4421-4424.

20. D. Kitagawa, R. Tanaka, and S. Kobatake, Phys. Chem. Chem. Phys., 2015, 17, 27300-27305.

21. S. Ohshima, M. Morimoto, and M. Irie, Chem. Sci., 2015, 6, 5746-5752.

22. H. Koshima, H. Nakaya, H. Uchimoto, and N. Ojima, Chem. Lett., 2012, 41, 107-109.

23. H. Koshima, N. Ojima, and H. Uchimoto, J. Am. Chem. Soc., 2009, 131, 6890-6891.

24. H. Koshima, and N. Ojima, Dyes Pigm., 2012, 92, 798-801.

25. O. S. Bushuyev, A. Tomberg, T. Friščić, and C. J. Barrett, J. Am. Chem. Soc., 2013, 135, 12556-12559.

26. O. S. Bushuyev, T. A. Singleton, and C. J. Barrett, Adv. Mater., 2013, 25, 1796-1800.

27. O. S. Bushuyev, T. C. Corkery, C. J. Barrett, and T. Friščić, Chem. Sci., 2014, 5, 3158-3164.

28. H. Koshima, R. Matsuo, M. Matsudomi, Y. Uemura, and M. Shiro, Cryst. Growth Des., 2013, 13, 4330-4337.

29. T. Kim, M. K. Al-Muhanna, S. D. Al-Suwaidan, R. O. Al-Kaysi, and C. J. Bardeen, Angew. Chem. Int. Ed., 2013, 52, 6889-6893.

30. T. Kim, L. Zhu, L. J. Mueller, and C. J. Bardeen, J. Am. Chem. Soc., 2014, 136, 6617-6625.

31. L. Zhu, R. O. Al-Kaysi, R. J. Dillon, F. S. Tham, and C. J. Bardeen, Cryst. Growth Des., 2011, 11, 4975-4983.

32. L. Zhu, R. O. Al-Kaysi, and C. J. Bardeen, J. Am. Chem. Soc., 2011, 133, 12569-12575.

33. L. Zhu, A. Agarwal, J. Lai, R. O. Al-Kaysi, F. S. Tham, T. Ghaddar, L. Mueller, and C. J. Bardeen, J. Mater. Chem., 2011, 21, 62586268

34. R. O. Al-Kaysi, A. M. Mueller, and C. J. Bardeen, J. Am. Chem. Soc., 2006, 128, 15938-15939.

35. R. O. Al-Kaysi, and C. J. Bardeen, Adv. Mater., 2007, 19, 1276 1280.

36. T. Kim, L. Zhu, L. J. Mueller, and C. J. Bardeen, CrystEngComm, 2012, 14, 7792-7799.

37. J. K. Sun, W. Li, C. Chen, C. X. Ren, D. M. Pan, and J. Zhang, Angew. Chem. Int. Ed., 2013, 52, 6653-6657.

38. P. Naumov, J. Kowalik, K. M. Solntsev, A. Baldridge, J.-S. Moon, C. Kranz, and L. M. Tolbert, J. Am. Chem. Soc., 2010, 132, 5845-5857.

39. T. Seki, K. Sakurada, M. Muromoto, and H. Ito, Chem. Sci., 2015, 6, 1491-1497.

40. D. Kitagawa, C. Iwaihara, H. Nishi, and S. Kobatake, Crystals, 2015, 5, 551-561.

41. S. Kobatake, K. Uchida, E. Tsuchida, and M. Irie, Chem. Commun., 2002, 2804-2805. 